\title{
Rituximab suppresses disease activity after natalizumab withdrawal: an exploratory study
}

\author{
Simona Malucchi ${ }^{1 *}$, Marco Capobianco ${ }^{1}$, Alessia di Sapio ${ }^{1}$, Marianna Lo Re ${ }^{2}$, Paola Cavalla ${ }^{3}$ and Antonio Bertolotto ${ }^{1}$
}

\begin{abstract}
Background: Natalizumab is highly effective in reducing multiple sclerosis disease activity; however it carries a risk of progressive multifocal leukoencephalopathy, that represents the main reason of drug discontinuation. After natalizumab withdrawal, reactivation of disease is soon observed and, until now, it is not known which treatment strategy should be followed after natalizumab discontinuation. Aim of this study is to evaluate rituximab efficacy in controlling disease activity after natalizumab withdrawal.
\end{abstract}

Case Presentation: Ten relapsing-remitting multiple sclerosis patients treated with natalizumab stopped it for the high risk of progressive multifocal leukoencephalopathy and started rituximab after a wash out period of two months; Second cycle of rituximab was planned in case of CD19+ cells increase and/or disease reactivation; brain MRI was performed before starting rituximab and then at six and twelve months after it.

Conclusions: All the patients showed disease stability during the wash out period.

Radiological stability was observed at 6 and at 12 months in all the patients; during the follow up two patients had exacerbation of sensitive symptoms without evidence of brain MRI activity.

This study gives evidence of rituximab efficacy in abolishing disease reactivation after natalizumab withdrawal.

Keywords: Multiple sclerosis, Natalizumab, Progressive multifocal leukoencephalopathy (PML), Rituximab

\section{Background}

Natalizumab has been confirmed as highly effective in reducing multiple sclerosis (MS) disease activity. However, it carries a risk of progressive multifocal leukoencephalopathy (PML), an opportunistic disease with high morbidity, that represents the major cause of natalizumab interruption.

Upon withdrawing natalizumab, resumption of disease activity is soon observed [1,2]. An unsolved problem is the lack of therapies able to abolish the risk of disease reactivation after natalizumab withdrawal.

Many strategies aiming at reducing the risk of disease reactivation have been tried; switching to first-line therapies or high dose corticosteroids failed to control the disease; literature data about the use of fingolimod

\footnotetext{
*Correspondence: simona.malucchi@gmail.com

'University Hospital San Luigi Gonzaga, SCDO Neurologia 2- Regional

Multiple Sclerosis Center, Regione Gonzole 10, 10043 Orbassano, Torino, Italy

Full list of author information is available at the end of the article
}

are controversial, but consensus exists about the need to short wash out period after natalizumab interruption $[3,4]$.

In this report we want to share our experience about the use of rituximab after natalizumab withdrawal with the aim to evaluate its efficacy in controlling disease course.

\section{Case Presentation}

Ten RR-MS patients ( 8 women and 2 male) have been treated with natalizumab for a median number of 38 infusions (range 22-76); patients had a median number of 2 relapses in the year preceding natalizumab in spite of disease modifying drugs (DMDs) and full response to natalizumab (neither clinical nor radiological activity during treatment); demographic and clinical characteristics are presented in Table 1. All the patients had high risk of PML, due to the association of a stratify index $>1.5$ and the elevated number of infusions. After consultation between neurologist and patient, decision to stop natalizumab was taken and patients have been proposed to switch to 
Table 1 Demographic and clinical characteristics

\begin{tabular}{lllllll}
\hline Gender & $\begin{array}{l}\text { Age at } \\
\text { natalizumab start }\end{array}$ & $\begin{array}{l}\text { Relapses in the year } \\
\text { before natalizumab }\end{array}$ & $\begin{array}{l}\mathrm{N}^{\circ} \text { of natalizumab } \\
\text { infusions }\end{array}$ & $\begin{array}{l}\text { EDSS after last } \\
\text { natalizumab infusion }\end{array}$ & $\begin{array}{l}\text { Brain MRI at } 6 \text { months } \\
\text { after rituximab }\end{array}$ & $\begin{array}{l}\text { Brain MRI at } 12 \text { months } \\
\text { after rituximab }\end{array}$ \\
\hline F & 29 & 2 & 35 & 1.5 & unchanged & unchanged \\
F & 44 & 2 & 76 & 3.5 & unchanged & unchanged \\
F & 32 & 1 & 27 & 2.0 & unchanged & unchanged \\
F & 38 & 2 & 69 & 2.0 & unchanged & unchanged \\
M & 25 & 1 & 37 & 4.5 & unchanged & unchanged \\
F & 33 & 2 & 39 & 3.5 & unchanged & unchanged \\
F & 40 & 1 & 22 & 2.0 & unchanged & unchanged \\
F & 30 & 2 & 67 & 3.5 & unchanged & n.a. \\
F & 35 & 2 & 71 & 2.0 & unchanged & n.a. \\
M & 32 & 2 & 30 & 7.0 & unchanged & unchanged \\
\hline
\end{tabular}

n.a. not available (follow up $<1$ year)

rituximab after a wash out period of 2 months; written informed consent was obtained from each patient; as the use of rituximab was off label, approval was obtained from the local ethics committee of the University Hospital San Luigi.

In our real-world clinical study median wash out period was 3.2 months (range 2-4.2 months).

The choice of rituximab was due to the impossibility of using fingolimod, because of cardiologic contraindication (2 patients), or patients' refusal (8 patients).

Each patient underwent gadolinium-enhanced brain MRI scan after the last infusion of natalizumab and two months later, in order to exclude signs suggestive for PML; than brain MRI was performed six and twelve months after rituximab infusion; MRI was performed in the same $1.5 \mathrm{~T}$ scanner using the same protocol for each patients; protocol included axial T2-weighted scans, coronal Flair-weighted scans, DWI sequences and postcontrast T1-weighted scans.

Rituximab was administered at the dosage of $375 \mathrm{mg} / \mathrm{mq}$ once/week for 4 weeks (I cycle); blood sample was taken monthly in order to count CD19+ cells; second cycle at the dosage of $1000 \mathrm{mg}$ at day 0 and 15 was planned in case of CD19+ increase and/or clinical or radiological disease reactivation.

Patients started rituximab from October 2013 to May 2014; median follow up after rituximab was 15.8 months (range 11.5-18.5 months).

\section{Results}

No patient had disease reactivation during the wash out period; brain MRI performed two months after the last natalizumab infusion was unchanged compared to the one performed immediately after the last infusion.

A brain MRI performed six months after rituximab infusions did not show contrast-enhancing lesions or an increase in the number of T2 lesions compared to the brain MRI that had been performed after the last natalizumab infusion. In patients with a follow up of one year (8 patients), brain MRI performed 12 months after rituximab was unchanged.

No patient experienced clinical rebound; two out of ten had a worsening of pre-existing sensitive symptoms: the first patient had an exacerbation of paresthesia in left limbs six months after rituximab, the second had exacerbation of paresthesia in left face nine months after rituximab; both patients were treated with intravenous steroids for 3 days; in both cases CD19 at the time of clinical relapse were detectable and II cycle of rituximab was administered; brain MRI in both cases showed disease stability.

Compared to EDSS after the last natalizumab infusion, EDSS was unchanged at six months in all the patients and at 12 months in patients with one year follow up.

\section{Conclusions}

This is a preliminary study, conducted on a small number of patients, aiming at the evaluation of rituximab efficacy after natalizumab withdrawal. The choice of rituximab was due to two main reasons: the evidence of efficacy in aggressive RR-MS patients [5] and the minor risk of PML compared to that of natalizumab $[6,7]$.

Furthermore, the use of rituximab was due to the impossibility of using fingolimod, because of bradycardia in 2 patients and patients' refusal in the other 8 patients; the use of ciclophosphamide was not taken into consideration because our study population was characterized by young people with desire for parenthood; patients would have to undergo fertility preservation procedures that would have extended the time of drug initiation. Alemtuzumab was not yet available at the time the study was conducted, so its use was not allowed.

This work shows rituximab is highly efficacious in controlling disease course after natalizumab discontinuation, 
as no patient had disease rebound, nor radiological reactivation at six months after rituximab infusion, that correspond to at least 8 months after natalizumab withdrawal.

Eight patients reached a follow up of one year and in these patients MRI at 12 months showed persistence of stability.

We observed two very mild relapses in two patients at six and nine months after rituximab, without brain MRI activity; in that circumstance the two patients showed an increase of CD19+ cells that required the second cycle of treatment.

A matter of concern in using Rituximab is the risk of PML; compared to natalizumab very little data are known about PML risk during rituximab treatment; data from rheumatologic experience suggest a PML risk of $1 / 25000$ in rheumatoid arthritis affected patients treated with rituximab, including both JCV positive and negative patients (6), whereas patients in our work had a risk of 1/120-1/145 [8].

Finally, at present there is no agreement on what would be the best posological scheme for rituximab in MS, including its duration. Different protocols have been suggested and applied: $375 \mathrm{mg}$ every week for 4 weeks [9] or $1000 \mathrm{mg}$ i.v. at day 0 and 15 [10]. Whatever regimen is adopted and despite the lower risk of PML, we believe that the use of rituximab to prevent breakthrough disease after natalizumab should be restricted to the first month after its discontinuation. Later on additional strategies have to be found. In our Clinic we are planning to use a standard regimen with retreatment six month after the first cycle of rituximab followed by a switch to another drug such as dimethyl fumarate.

Despite the small number of patients this study has two strong points: 1) patients had similar disease features before natalizumab initiation with very active course, and high risk of disease reactivation after its interruption; brain MRI were performed at the same time points with the same scanner and same protocol; 2) it shows rituximab appears an efficacious strategy to manage natalizumab discontinuation; therefore we think our experience needs to be shared.

\section{Authors' contributions}

SM, MC, AdS, and MLR participated in the selection of patient, clinical evaluation of patients and coordination of the study; PC participated in selection and clinical evaluation of patients; $A B$ participated in the design of the study. All authors read and approved the final manuscript.

\section{Competing interests}

The authors declare that they have no competing interests.

\section{Consent statement}

Written informed consent was obtained from the patients for publication of these case reports. A copy of the written consent is available for review by the Editor-in-Chief of this journal.

\section{Disclosure}

Dr Simona Malucchi, Dr Marco Capobianco, Dr Antonio Bertolotto received consultation and speaking fees from Sanofi-Genzyme, Biogen-ldec, Merck-Serono, Novartis and Teva; Dr Alessia di Sapio received consultation and speaking fees from Biogen-Idec, Merck Serono, Teva and Novartis.

Dr Paola Cavalla.

Dr Marianna Lo Re has nothing to disclose.

\section{Author details}

${ }^{1}$ University Hospital San Luigi Gonzaga, SCDO Neurologia 2- Regional Multiple Sclerosis Center, Regione Gonzole 10, 10043 Orbassano, Torino, Italy. 2Dipartimento di Biomedicina Sperimentale e di Neuroscienze Cliniche, Università di Palermo, Via del Vespro 129, 90127 Palermo, Italy. ${ }^{3}$ Department of Neuroscience and Mental Health, Health and Science City, University Hospital of Turin, MS Center, I Neurologic Clinic, Via Cherasco 15, 10126 Torino, Italy.

Received: 2 July 2015 Accepted: 24 May 2016

Published online: 07 July 2016

\section{References}

1. O'Connor PW, Goodman A, Kappos L, Lublin FD, Miller DH, Polman C, et al. Disease activity return during natalizumab treatment interruption in patients with multiple sclerosis. Neurology. 2011;76:1858-65.

2. Sorensen PS, Koch-Henriksen N, Petersen T, Ravnborg M, Oturai A, Sellebjerg F. Recurrence of rebound of clinical relapses after discontinuation of natalizumab therapy in highly active MS patients. J Neurol. 2014;261(6):1170-7. doi:10.1007/s00415-014-7325-8. Epub 2014 Apr 12.

3. Laroni A, Brogi D, Milesi V, Abate L, Uccelli A, Mancardi G. Early switch to fingolimod may decrease the risk of disease recurrence after natalizumab interruption. Mult Scler. 2013;19(9):1236-7.

4. Cohen M, Maillart E, Tourbah A, De Seze J, Vukusic S, Brassat D, et al. Switching from natalizumab to fingolimod in multiple sclerosis: a French prospective study. JAMA Neurol. 2014;71(4):436-41.

5. Naismith RT, Piccio L, Lyons JA, Lauber J, Tutlam NT, Parks BJ, et al. Rituximab add-on therapy for breakthrough relapsing multiple sclerosis. A 52-week phase II trial. Neurology. 2010;74:1860-7.

6. Palazzo E, Yahia SA. Progressive multifocal leukoencephalopaty in autoimmune disease. Joint Bone Spine. 2012;79(4):351-5.

7. Carson KR, Focosi D, Major EO, Petrini M, Richey EA, West DP, et al. Monoclonal antibody-associated progressive multifocal leukoencefalophaty in patients treated with rituximab, natalizumab, and efalizumab: a review from the Research ion Adverse Drug Events and Reports (RADAR) project. Lancet Oncol. 2009:10(8):816-24.

8. Plavina T, Subramanyam M, Bloomgren G, Richman S, Pace A, Lee S, et al. Anti-JC Virus Antibody Levels in Serum or Plasma Further Define Risk of Natalizumab-Associated Progressive Multifocal Leukoencephalopathy. Ann Neurol. 2014:76(6):802-12.

9. Castillo-Trivino T, Braithwaite D, Bacchetti P, Waubant E. Rituximab in Relapsing and Progressive Forms of Multiple Sclerosis: A Systematic Review. Plos One. 2013;8(7), e66308.

10. Bar-Or A, Calabresi PAJ, Arnold D, Markowitz C, Shafer S, Kasper LH, et al. Rituximab in Relapsing-Remitting Multiple Sclerosis: A 72-Week, Open-Label, Phase I Trial. Ann Neurol. 2008;63:395-400.

Submit your next manuscript to BioMed Central and we will help you at every step:

- We accept pre-submission inquiries

- Our selector tool helps you to find the most relevant journal

- We provide round the clock customer support

- Convenient online submission

- Thorough peer review

- Inclusion in PubMed and all major indexing services

- Maximum visibility for your research 